\title{
Evaluation of joints in granitic outcrops for dimension stone exploitation
}

\author{
L.M.O. Sousa \\ Department of Geology, University of Trás-os-Montes e Alto Douro, Apartado 1013, 5001-801 Vila Real, \\ Portugal \\ (e-mail: Isousa@utad.pt)
}

\begin{abstract}
Visual impacts are common in dimension stone exploitation as a result of the excess of raw material abandoned in the vicinity of quarries, mainly when the fracture characteristics do not allow large blocks to be obtained. Quarry management is extremely dependent on natural block size. Therefore a small variation in joint characteristics would be significant for block size assessment. For this reason, the main objective of this study is to evaluate the influence of the joint characteristics on block size assessment and define a more reliable fracturation index for purposes of dimension stone. According to the conclusions obtained from the study of joints, Weighted Jointing (WJ) is defined by considering the jointing characteristics such as the weight of each joint set, joint median spacing, random joints, and geometry of joint sets. To achieve this purpose, an evaluation of joints was performed in outcrops and quarries of 10 granites located in the Vila Real region (Portugal). The results are unequivocal about the importance of considering the various joint characteristics to improve block size assessment and to reduce the risk in granite exploitation.
\end{abstract}

Rock material properties, joint characteristics, and degree of jointing are the more important parameters in rock mass behaviour. For profitable quarrying a rock mass with an appropriate degree of jointing is essential (Selonen et al. 2000; Carvalho et al. 2008). Degree of jointing comprises the density of joints (measured as joint-set spacing, block size, rock quality designation), the block shape or jointing pattern, and the orientation of joint set or main discontinuities (Palmström 1996). Studies of the degree of jointing by means of block size evaluation are frequently found in research papers (Hudson \& Priest 1979; Toyos et al. 1994; Lu \& Latham 1999; Palmström 2001, 2005; Wang et al. 2003; Sonmez et al. 2004; Kalenchuk et al. 2006; Latham et al. 2006), but there are few studies dealing with dimension stone (Taboada et al. 2006; Nikolayev et al. 2007; Prissang et al. 2007; Sousa 2007; Carvalho et al. 2008).

Several methods were proposed to evaluate the jointing degree of rock masses. Pettifer \& Fookes (1994) proposed the fracture spacing index, $I_{f}$, expressed by fractures per metre or mean spacing, estimated after spacing measures along two perpendicular scan-line surveys. Castaing \& Rabu (1981) defined the structural parameter taking into consideration the number of discontinuities per metre and the number of joint sets with the exclusion of the sub-horizontal jointing. The volumetric joint count, $J_{v}$ (ISRM 1978), defined as the sum of the number of discontinuities per metre in a perpendicular direction for each discontinuity set, is frequently used in block size assessment, and is given by the equation

$$
J_{v}=\frac{N_{1}}{L_{1}}+\frac{N_{2}}{L_{2}}+\frac{N_{3}}{L_{3}}+\ldots
$$

where $N$ is the number of discontinuities and $L$ is the length of scan-line in a perpendicular direction for each discontinuity set present (1, 2 and 3$)$. When the mean joint spacing is obtained, $J_{v}$ is calculated as follows (Palmström 1982):

$$
J_{v}=\frac{1}{S_{1}}+\frac{1}{S_{2}}+\frac{1}{S_{3}}+\ldots
$$

where $S_{1}, S_{2}$, and $S_{3}$ are the mean joint spacing, obtained by measuring in a perpendicular direction to each discontinuity set (1, 2 and 3). Palmström (2000) included random joints by using the equation

$$
J_{v}=\frac{1}{S_{1}}+\frac{1}{S_{2}}+\frac{1}{S_{3}}+\ldots+\frac{N r}{5}
$$

where $\mathrm{Nr}$ is the number of random joints. For heavily jointed rock masses, Sonmez \& Ulusay (2002) proposed the equation

$$
J_{v}=D_{n} \frac{1}{S}
$$

where $D_{n}$ is the estimated number of joint sets and $S$ is the average size of the blocks. $D_{n}$ is estimated by counting the number of surfaces of natural rock blocks.

According to the $J_{v}$ value, it is possible to obtain an idea about the dimension of rock blocks delimited by natural fractures (Table 1). Large blocks are necessary in the dimension stone industry, and therefore $J_{v}$ must be <3.0. Munõz de la Nava et al. (1989) and García (1996) established 2.0 as the $J_{v}$ threshold for obtaining blocks with appropriate size, and Sousa (2007) used this index for comparing the jointing characteristics between several places. Correct estimation of block size is extremely important in the quarry exploration stage, as there is a narrow line between success and failure. 
Table 1. Relationship between $\mathrm{J}_{\mathrm{v}}$ and block size

\begin{tabular}{lcc}
\hline $\begin{array}{l}\text { Description } \\
\text { (ISRM 1978) }\end{array}$ & $\begin{array}{c}\left.J_{v} \text { (joints } \mathrm{m}^{-3}\right) \\
\text { (ISRM 1978) }\end{array}$ & $\begin{array}{c}\text { Volume }\left(\mathrm{m}^{3}\right) \\
\text { (Toyos et al. 1994) }\end{array}$ \\
\hline Very large blocks & $<1.0$ & $>25$ \\
Large blocks & $1-3$ & $1-25$ \\
Medium blocks & $3-10$ & $0.025-1$ \\
Small blocks & $10-30$ & $0.001-0.025$ \\
Very small blocks & $>30$ & $<0.001$ \\
\hline
\end{tabular}

From the literature, the importance of several parameters for block size assessment is evident; these include number of joint sets and discontinuity spacing (Nefeslioglu et al. 2006). However, some uncertainties in block size estimation are evident when areas with different jointing have similar values and vice versa. Parameters such as distribution of spacing data, different number of spacing data in joint sets, angles between joint sets, and random joints are some reasons for such uncertainties. The stone industry requires large blocks and the risk in block size assessment must be eliminated or reduced to minimum levels.

Joint spacing commonly has a lognormal or exponential distribution (Priest 1993). Therefore, the calculation of block size based on mean spacing will cloud the results. Usually one joint set is predominant but no weighting of joint sets is considered, so the $J_{v}$ value does not reflect accurately the block size. Two sub-vertical and perpendicular joint sets are the ideal jointing pattern for quarrying, and deviations from this condition should be considered in block size assessment. Random joints affect the recovery rate of the mineral deposit, but their importance is not related to only the number of joints, and the recovery index should reflect this fact.

In this study, the influence of the parameters mentioned above is evaluated, and approaches are defined to overcome the usual limitations found when block size index is used for granite exploration. Weighted Jointing $(W J)$ is defined to reduce or avoid the uncertainties and restrictions summarized above. WJ was applied in selected outcrops and quarries for 10 granites in NE Portugal.

\section{Granites studied and methods}

The studied rocks in NE Portugal are medium- to coarse-grained post-tectonic and syntectonic granites of the third phase of the Hercynian orogeny (Fig. 1). Some have a porphyritic texture (Sousa et al. 2005), and some have been exploited for dimension stone (Sousa 2000).

The exploration stage in the dimension stone industry is often neglected because of both the cost and the lack of an appropriate method. Usually it is not possible to study the rock mass by drill core because the low price of the raw material forbids the use of expensive techniques, and thus it is necessary to obtain all the fracture information from surface observation. The fracture traces were measured in several outcrops of the studied granites. Obviously the sub-horizontal jointing is not accessible in superficial surveys and was not considered in this study. Horizontal joints originate by release of pressure, and follow the present erosion level, whereas the developing fissures decrease at depth (Marit et al. 2009; Ren \& Nie 2009). Massive granites show a decrease in the sub-horizontal jointing at depth (Carlsson \& Olsson 1978; Blès \& Feuga 1981; Dutartre 1982; Marre 1986; Hisanaga et al. 1993) and therefore these joints are not prejudicial to rock exploitation (Sousa 2000, 2007; Morais 2003). The author has no knowledge of quarries abandoned because of an abnormal density of horizontal joints, and the exploitation will be feasible if the other joint characteristics are favourable. According to the data obtained in granite quarries of NE Portugal (Sousa 2000, 2007; Morais 2003), the joints are mostly sub-vertical and the joint trace is a consistent measure of the joint direction. Consequently, the method used is appropriate, as error is neglected when the perpendicular distance between fracture traces is considered instead of the distance between fracture planes.

A total of 80 outcrops and 14 quarries were selected where a detailed jointing study was carried out by observation of joint traces, according to the method employed by Sousa (2007). In the selected outcrops an area of at least $50 \mathrm{~m} \times 50 \mathrm{~m}$ was selected (some are as large as $100 \mathrm{~m} \times 50 \mathrm{~m}$ ), whereas in quarries only the slope faces were accessible. In the studied areas, the set identification and spacing measures allow us to identify the orientation of joint sets, the spacing data for each set, and the presence of random joints. The conventional scan-line survey is widely used (Escuder Viruete et al. 2001; Latham et al. 2006; Carvalho et al. 2008) but is problematic when the joint sets have a non-random distribution because of the orientation sampling biases. The method used requires some practice in joint trace observation and a large amount of fieldwork, but gives a clear image of the jointing pattern and eliminates the orientation sampling biases of linear surveys. Based upon orientation data, joints were grouped in sets, and the spacing data were associated with these joint sets. Usually the joints in the studied granites belong to distinguishable sets, so that the detailed work proposed by Jimenez-Rodrigues \& Sitar (2006) for joint-set identification was not necessary. When a joint set has few spacing data, the joints are classified as random. A total of 3944 spacing data obtained were grouped in 175 joint sets, and random joints provided 952 spacing data.

\section{Weighted Jointing}

The definition of the $W J$ was achieved by analysis of the parameters that influence the assessment of block size. 


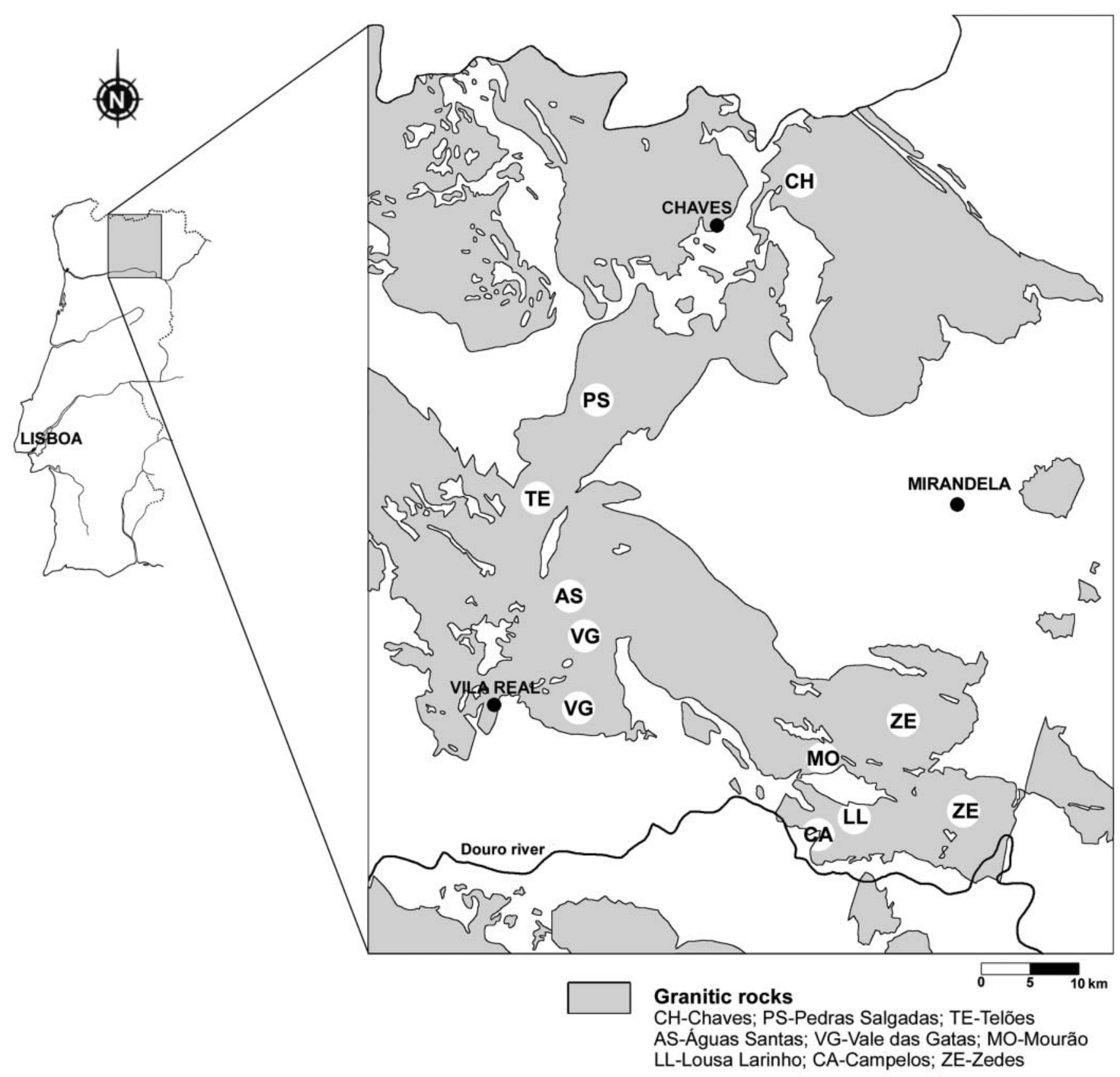

Fig. 1. Locations of the studied granites.

We analysed these parameters considering the literature review and the data obtained in this study, and describe the results in the following sections.

\section{Joint spacing distribution}

The assessment of block size according to Palmström (1982) (equation (2)) is based on mean joint spacing of the joint sets recognized in the rock mass. Joint-spacing distribution of overall spacing data of studied granites best fits the lognormal distribution as represented in Figure 2. Similar distributions (i.e. exponential, logarithmic and gamma) are found when I analyse the spacing data from each studied place and from each joint set. These joint spacing distributions are common in the literature (Priest \& Hudson 1976, 1981; Hudson \& Priest 1979; Kulatilake et al. 1993; Priest 1993; Hudson \& Harrison 1997; Wines \& Lilly 2002; Nefeslioglu et al. 2006; Rafiee \& Vinches 2008; Kalenchuk et al. 2008) and therefore the mean spacing is not the best parameter to characterize the average of the distribution. When the distributions have an excess of high or low values, the mean does not reflect the central tendency, which is better illustrated by the median (Davis 1986). In such highly skewed distributions, the median is lower (Fig. 3) 


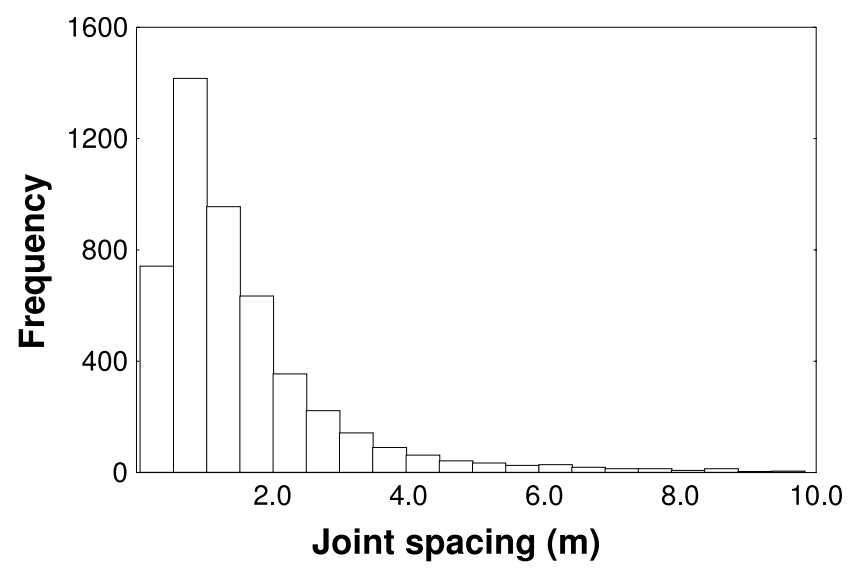

Fig. 2. Distribution of joint spacing in studied granites (4896 data).

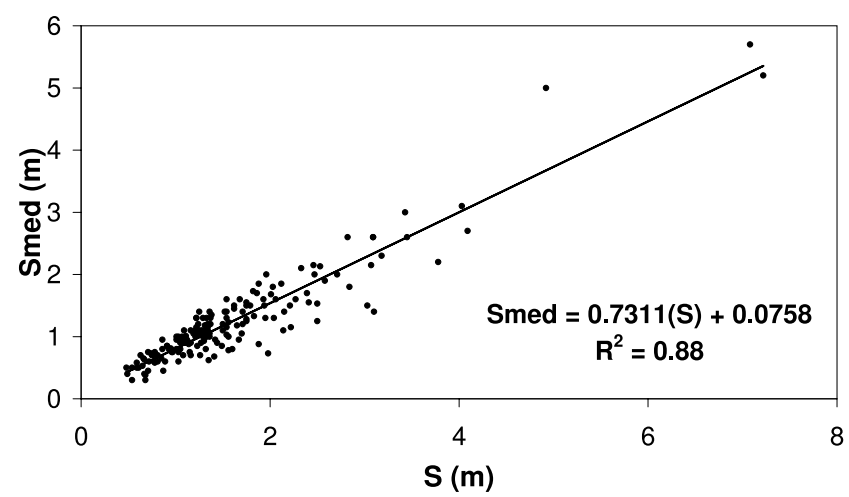

Fig. 3. The median spacing (Smed) is lower than the mean spacing $(S)$ (175 joint sets).

and less sensitive to extreme scores than the mean (Bickel 2003).

According to the above assessment, I achieve block size evaluation by using the equation

$$
\text { Jmed }=\frac{1}{\text { Smed }_{1}}+\frac{1}{\text { Smed }_{2}}+\frac{1}{\text { Smed }_{3}}+\ldots
$$

where Smed $_{1}$, Smed $_{2}$, Smed $_{3}$ are the median joint spacing obtained by measuring in a perpendicular direction to each discontinuity set (1, 2 and 3 ). Considering the relation between median spacing and mean spacing (the first is lower), Jmed is higher than $J_{v}$ and consequently the block size value will be worse. Equation (5) is the basis for the $W J$ definition, according to the factors considered in the following sections.

\section{Joint-set weight}

Joint distribution in rock is not random, as there are commonly zones with high density of joints close to massive zones. On the other hand, the area of observation is not geometric, but is a consequence of factors such as soil cover, topography and outcrop shape. Usually one joint set is predominant in granitic rocks. Therefore it is unlikely that each joint set will have an equal number of spacing data. The block size assessment

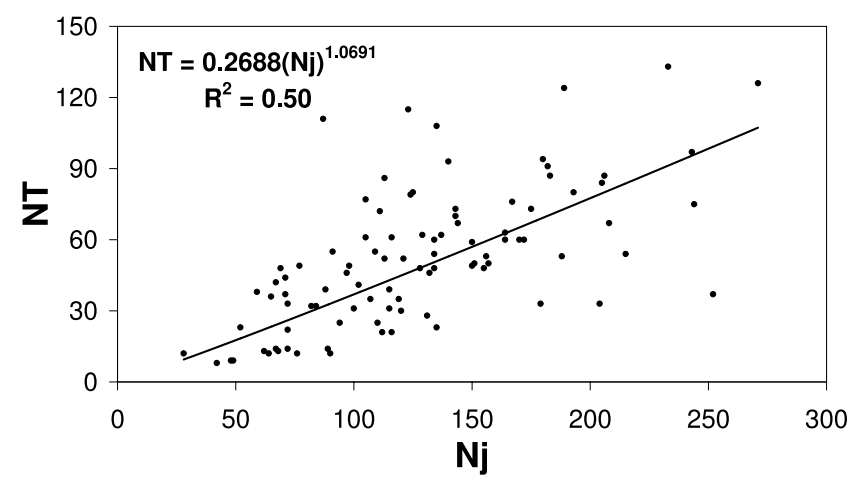

Fig. 4. Number of spacing data $(N T)$ and number of joints identified $(N j)$.

considers joint sets with the same weight, and the values obtained are clouded when joint sets with few data are present. To overcome this limitation, I propose the weighting of joint sets in agreement with their importance in rock mass. Weighting of each joint set can use several approaches, such as the proportion of the number of joints, the proportion of the total spacing, and the proportion of the number of spacing data. The first approach is not suitable when heavily jointed zones are present in the rock mass, as a small portion of the studied area will influence the index value for the entire area. Furthermore, isolated joints have little influence on rock exploitation and counting them introduces a bias in the outcrop evaluation. Joints with no relation to other joints in the vicinity are common because of factors such as the geometry of the outcrop and soil or lichen cover. For these reasons, some joints are not used in spacing measurements and it is impossible to evaluate accurately their contribution to the subdivision of the rock mass. This situation is clearly represented in Figure 4, where we can see the relationship between the number of joints and the number of spacing data at the studied sites. The joints with more importance in rock mass subdivision will be enhanced by using the number of spacing data or their sum.

Considering the number of spacing data of each joint set $\left(N S_{s i}, i=1,2,3, \ldots\right)$, the total number of spacing data in joint sets $\left(N S_{j s}\right)$ and the number of joint sets $\left(N_{j s}\right)$, the joint-set weighting $\left(W_{N S_{i}}, i=1,2,3, \ldots\right)$ is calculated with the equation

$$
W_{N S_{i}}=\frac{N S_{s i}}{N S_{j s}} \times N_{j s}
$$

When the sum of spacing is taken into account, joint-set weighting $\left(W_{S S_{i}}, i=1,2,3, \ldots\right)$ is as follows:

$$
W_{S S_{i}}=\frac{S S_{s i}}{S S_{j s}} \times N_{j s}
$$

where $S S_{s i}$ is the sum of spacing data in each joint set $(i=1,2,3, \ldots), S S_{j s}$ is the total sum of spacing data in joint sets and $N_{j s}$ is the number of joint sets. With these formulae the joint sets will be considered according to 

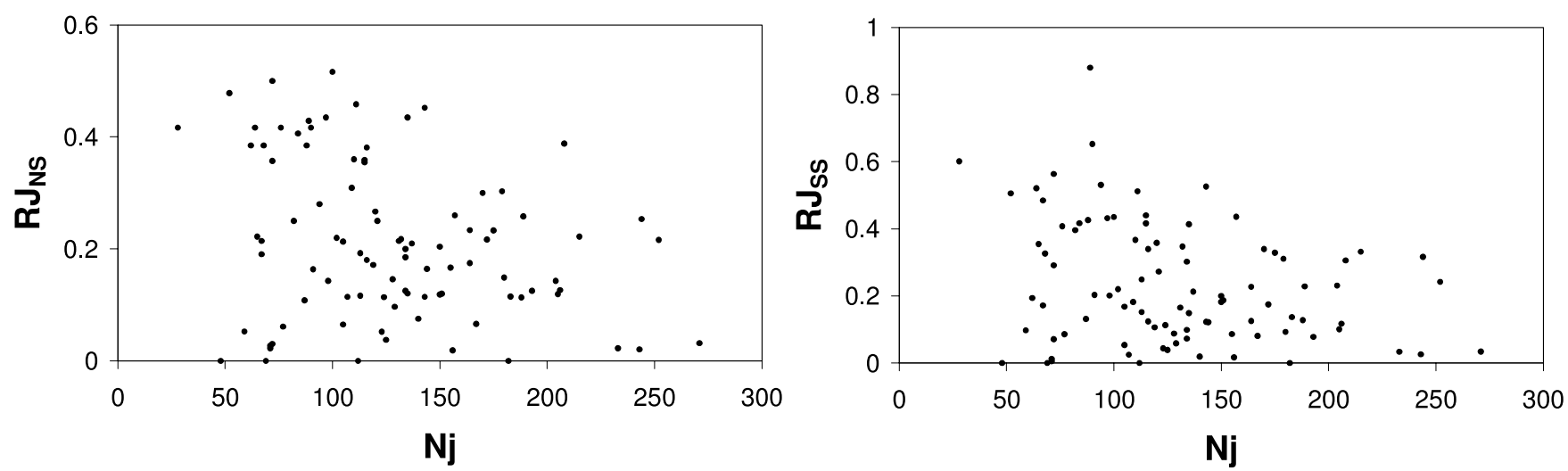

Fig. 5. Relationship between the random joint factors $\left(R J_{N S}\right.$ and $\left.R J_{S S}\right)$ and the number of joints $(N j)$.

their importance in the joint pattern, otherwise their weight will be equal to unity.

\section{Random joints}

This factor is influenced by the number of observations, as usually $15-20 \%$ of the discontinuities are classified as random joints (Wang et al. 2003). Therefore, their weight must be according to their proportion in the joint pattern, otherwise $W J$ will show an unrealistic increase when there is a high number of random joints. As stated above, a joint is considered as random when it is in a set with a low number of spacing data. Isolated joints (i.e. without data spacing) are rare and were not considered.

The weighting of random joints can be determined according to the number or the sum of spacing data of random joints by the equations

$$
\begin{aligned}
R J_{N S} & =\frac{N S_{r j}}{N T} \\
R J_{S S} & =\frac{S S_{r j}}{S T}
\end{aligned}
$$

where $R J_{N S}$ and $R J_{S S}$ are the random joint factors calculated by using respectively the number and the sum of spacing data of random joints, $N S_{r j}$ is the number of spacing data of random joints, $N T$ is the total number of spacing data, $S S_{r j}$ is the sum of spacing data of random joints and $S T$ is the total sum of the spacing data. Random joint factors $\left(R J_{N S}\right.$ and $\left.R J_{S S}\right)$ usually take values above 0.5 , having a similar mean $\left(R J_{N S}=0.22\right.$; $\left.R J_{S S}=0.24\right) . R J_{S S}$ is higher than $R J_{N S}$ because the spacing data from random joints are slightly higher than those of joint sets, but this difference is not significant. In the studied granites, the proportion of spacing data from random joints decreases with the rise of the number of spacing data, and the same occurs with $R J_{N S}$ and $R J_{S S}$ in relation to the number of joints (Fig. 5). Thus there is an abnormal increase of $W J$ in places with few joints and spacing data. Observation zones with larger areas will give a more correct image of
Table 2. Geometric factor (Gf) and the number of joint sets

\begin{tabular}{lccc}
\hline $\begin{array}{l}\text { Number of } \\
\text { joint sets }\end{array}$ & $\begin{array}{c}\text { Number of } \\
\text { places }\end{array}$ & $\begin{array}{c}G f \\
\text { range }\end{array}$ & $\begin{array}{c}G f \\
\text { mean }\end{array}$ \\
\hline 0 & 2 & - & - \\
1 & 27 & 0 & 0 \\
2 & 53 & $0-0.51$ & 0.11 \\
3 & 6 & $0.49-0.66$ & 0.58 \\
4 & 6 & $0.58-0.92$ & 0.80 \\
\hline
\end{tabular}

the fracture pattern, avoiding underestimation of the mineral potential of the rock mass.

\section{Jointing geometry}

Block size estimation does not consider the geometry of the joint sets, but when two sets are not perpendicular the yield of a mineral deposit will be lower. Joint patterns with more than two sub-vertical joint sets are very restrictive in granite exploitation and any recovery index must consider this fact. The geometric factor $(G f)$ is proposed, defined according to the angles between joint sets:

$$
G f=1-\left[\prod_{i=1}^{n-1} \sin \left(j_{i}, j_{z}\right)_{z=i+1, \ldots, n}\right]
$$

where $j_{i}$ and $j_{z}$ are joint sets. Joint patterns with two perpendicular joint sets give $G f=0$, whereas lower angles and more than two joint sets will increase the $G f$ value. In the studied granites, $G f$ has lower values, as two nearly perpendicular sub-vertical joint sets are common. The overall mean of $G f$ is 0.15 and the number of joint sets obviously increases the $G f$ value (Table 2).

\section{Definition of Weighted Jointing}

In this section the equations for $W J$ computation are presented, considering the factors recognized above, such as the joint-set weighting $\left(W_{N S}\right.$ and $\left.W_{S S}\right)$, the random joint factor $\left(R J_{N S}\right.$ and $\left.R J_{S S}\right)$, and the geometric factor $(G f)$. Considering the number of spacing data, the weighted jointing $\left(W_{N S} J\right)$ is given by the equation 
Table 3. Factors considered in estimation of the block size

\begin{tabular}{|c|c|c|c|c|c|c|c|}
\hline \multirow[t]{2}{*}{ Indices } & \multicolumn{7}{|c|}{ Factors } \\
\hline & $\begin{array}{c}\text { Mean } \\
\text { spacing }\end{array}$ & $\begin{array}{l}\text { Median } \\
\text { spacing }\end{array}$ & $\begin{array}{c}\text { Joint-set } \\
\text { weight (NS) }\end{array}$ & $\begin{array}{c}\text { Joint-set } \\
\text { weight (SS) }\end{array}$ & $\begin{array}{l}\text { Random } \\
\text { joints (NS) }\end{array}$ & $\begin{array}{l}\text { Random } \\
\text { joints (SS) }\end{array}$ & $\begin{array}{l}\text { Joint-set } \\
\text { geometry }\end{array}$ \\
\hline$J v^{*}$ & • & & & & & & \\
\hline Jmed & & $\bullet$ & & & & & \\
\hline$W_{N S} J$ & $\bullet$ & & $\bullet$ & & $\bullet$ & & - \\
\hline$W_{N S}$ Jmed & & $\bullet$ & $\bullet$ & & $\bullet$ & & $\bullet$ \\
\hline$W_{S S} J$ & $\bullet$ & & & $\bullet$ & & $\bullet$ & $\bullet$ \\
\hline$W_{S S}$ Jmed & & $\bullet$ & & $\bullet$ & & $\bullet$ & $\bullet$ \\
\hline
\end{tabular}

* According to Palmström (1982).

NS, number of spacing data; SS, sum of spacing data.

$$
W_{N S} J=\sum_{i=1}^{n} \frac{1}{S_{i}} \times W_{N S_{i}}+R J_{N S}+G f
$$

where $S_{i}$ is the mean spacing, $W_{N S_{i}}$ is the joint-set weight (equation (6)), $R J_{N S}$ is the random joint weight (equation (8)), and $G f$ is the geometric factor (equation (10)).

When the sum of spacing data is considered, weighted jointing $\left(W_{S S} J\right)$ is defined as follows:

$$
W_{S S} J=\sum_{i=1}^{n} \frac{1}{S_{i}} \times W_{S S_{i}}+R J_{S S}+G f
$$

where $S_{i}$ is the mean spacing, $W_{S S_{i}}$ is the joint-set weight (equation (7)), $R J_{S S}$ is the random joint weight (equation (9)), and $G f$ is the geometric factor (equation (10)).

Weighted jointing can also be estimated using the median spacing:

$$
\begin{aligned}
& W_{N S} \text { Jmed }=\sum_{i=1}^{n} \frac{1}{\text { Smed }_{i}} \times W_{N S_{i}}+R J_{N S}+G f \\
& W_{S S} J_{m e d}=\sum_{i=1}^{n} \frac{1}{\text { Smed }_{i}} \times W_{S S_{i}}+R J_{S S}+G f
\end{aligned}
$$

where Smed $_{i}$ is the median joint spacing obtained by measuring in a perpendicular direction to each discontinuity set. It is possible to estimate the rock-block size with several equations, according to different factors (Table 3).

\section{Application}

In the studied areas, the block size assessment was performed by using $J_{v}$ (equation (2)), Jmed (equation (5)), and the various versions of Weighted Jointing ( $W_{N S} J$, equation (11), $W_{N S} J m e d$, equation (12), $W_{S S} J$, equation (13) and $W_{S S} J m e d$, equation (14)).

These indices best fit gamma ( $J_{v}$ and Jmed) and lognormal (other indices) distributions, as represented in Figure 6. Analysis of the distributions of these indices indicates that in their comparison we should use the median instead of the mean. As expected from the relationship between mean and median spacing (Fig. 3), Jmed is higher than $J_{v}$. The use of the geometric factor $(G f)$ and the random joints factor $\left(R J_{N S}, R J_{S S}\right)$ increases the index value. Despite the random joints factor taking higher values when we consider the sum of spacing data $\left(R J_{S S}>R J_{N S}\right), W_{N S} J m e d$ is higher than $W_{S S} J m e d$. The explanation for this difference comes from the numerous spacing data in joint sets with low median spacing. $W_{N S} J m e d$ has higher values and its use is proposed to diminish the risk in choosing the best places for granite exploration.

These indices are related, as is evident from the high values of the Spearman rank correlation coefficients (Table 4), and regression analysis makes it possible to predict one index from another. In Figure 7 we can see some of the relationships between the indices, which all have high determination coefficients $\left(R^{2}\right)$.

Considering $W_{N S} J m e d=2.0$ as the threshold for profitable rock exploitation (Munõz de la Nava et al., 1989; García, 1996), the study areas must be rearranged in terms of their suitability for quarrying. With this boundary $\left(W_{N S} J m e d=2.0\right)$ and the correlations established in this study (Fig. 7), areas with $J_{v}>1.30$ or Jmed $>1.69$ are not suitable for quarrying. In fact, the new results show a clear diminution of the number of exploitable places, from $67(72.8 \%$ of the total) to $47(51.1 \%$ of the total) (Fig. 8), when we use the $W_{N S} J m e d$ index instead of $J_{v}$. The number of studied areas is very different from granite to granite, making it unfeasible to use mean values, and making the comparison between different granites difficult. When we use several approaches in block size assessment the difference in the suitability for quarrying is obvious. By means of the $W_{N S} J m e d$ index, four granites have a mean greater than 2.0 (PS, Pedras Salgadas; AS, Águas Santas; VG, Vale das Gatas; AR, Arejadouro) whereas using the $J_{v}$ index only one (AS, Águas Santas) exceeds the limit. The result obtained in Pedras Salgadas granite (observation in quarries) is atypical and may be a consequence of the set geometry at the time of the field study. In fact, this granite, like the others, has areas where the density of 

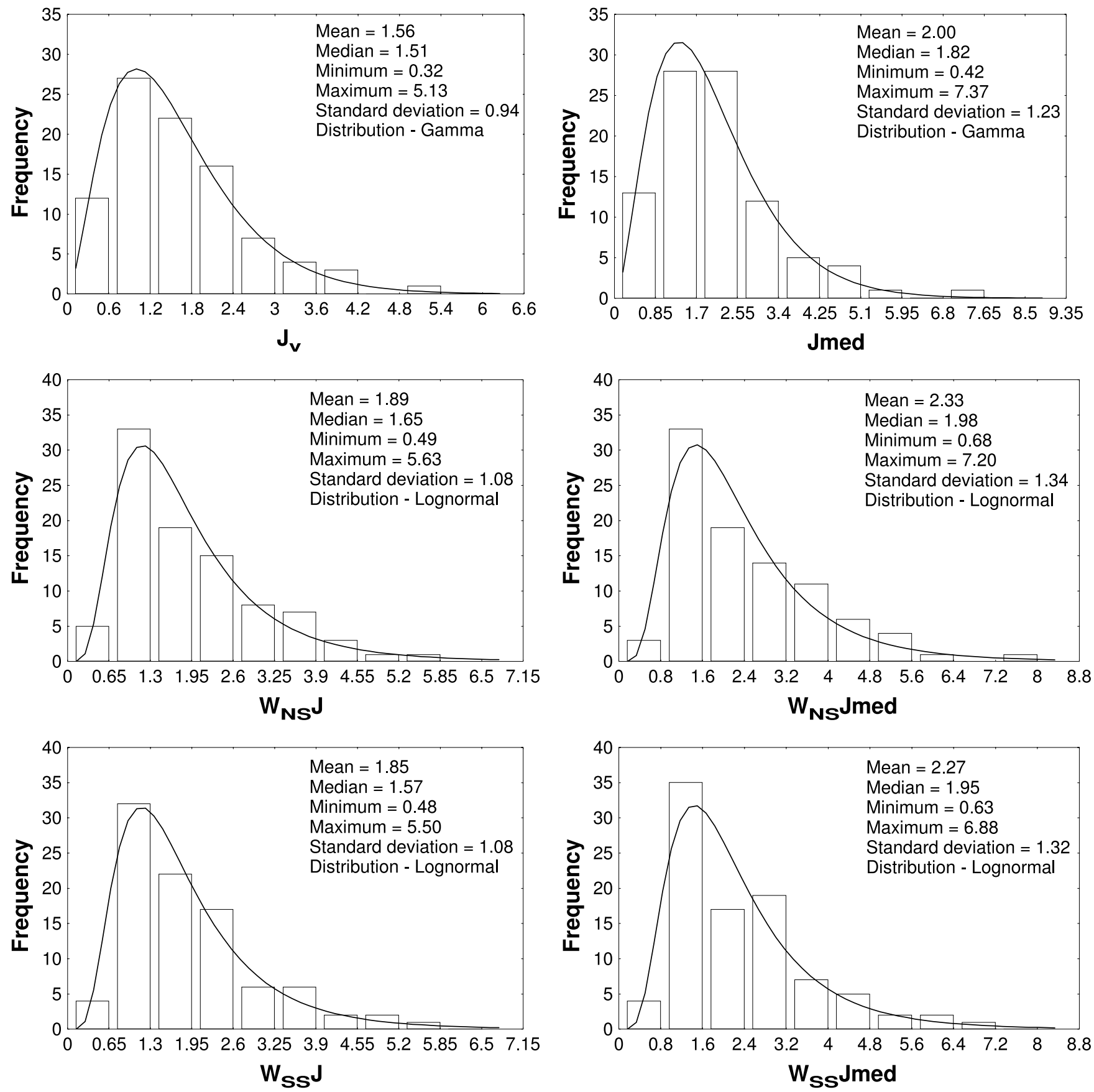

Fig. 6. Distributions of $J_{v}$, Jmed and $W J$ in studied areas.

Table 4. Spearman rank correlation coefficients between indices

\begin{tabular}{|c|c|c|c|c|c|c|}
\hline & $J_{v}$ & Jmed & $W_{N S} J$ & $W_{N S} J$ med & $W_{S S} J$ & $W_{S S}$ Jmed \\
\hline$J_{v}$ & 1 & & & & & \\
\hline Jmed & 0.96 & 1 & & & & \\
\hline$W_{N S} J$ & 0.96 & 0.94 & 1 & & & \\
\hline$W_{N S} J$ med & 0.92 & 0.96 & 0.96 & 1 & & \\
\hline$W_{S S} J$ & 0.94 & 0.89 & 0.96 & 0.91 & 1 & \\
\hline$W_{S S} J$ med & 0.91 & 0.94 & 0.96 & 0.98 & 0.93 & 1 \\
\hline
\end{tabular}

jointing is higher, and when exploitation occurs across these areas the density of jointing will obviously increase. Another important factor to consider in this analysis is the observation along the face slopes, which is different from observations of rock outcrops in the other granites. This avoids the observation of a large number 

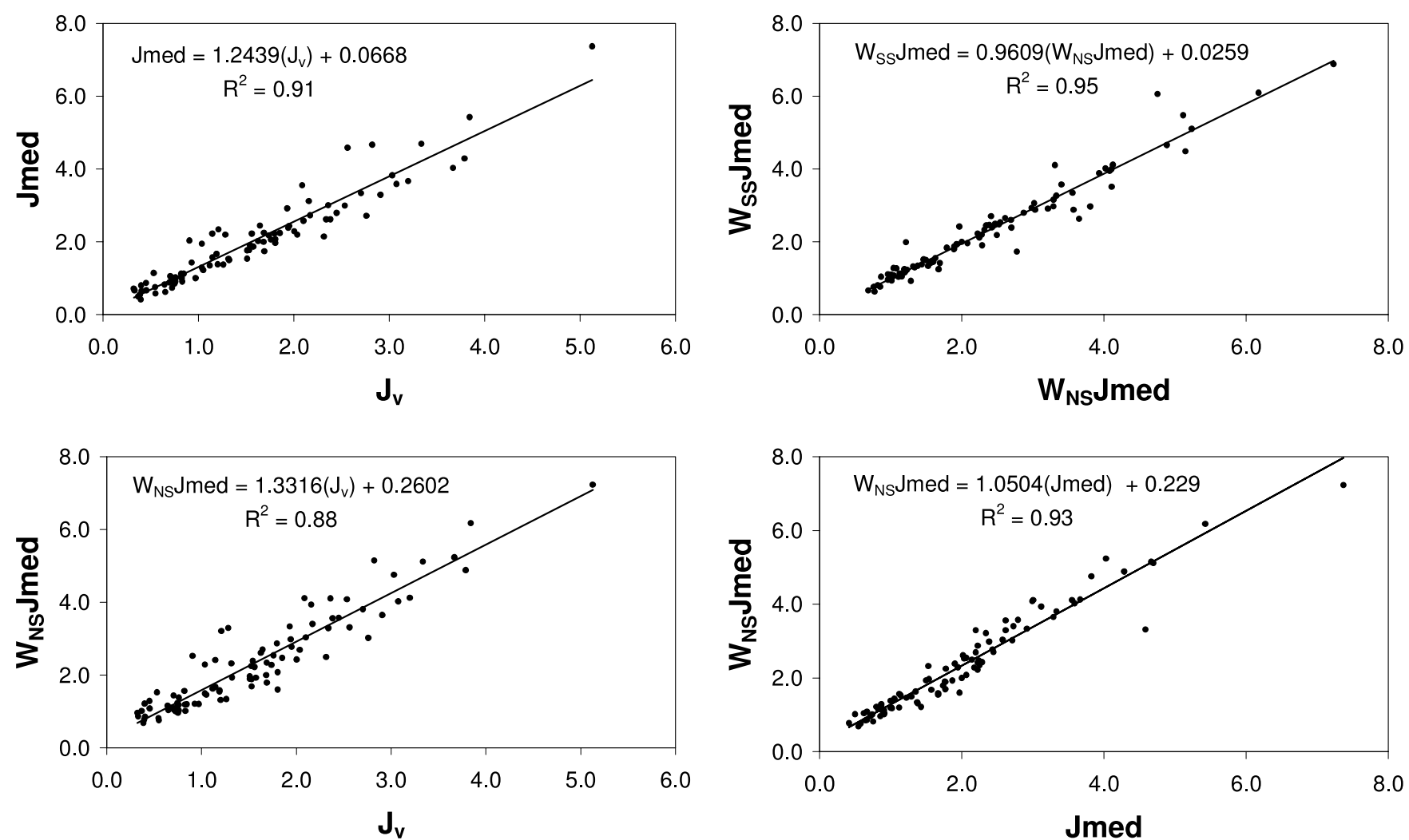

Fig. 7. Relationship between some of the block size indices.
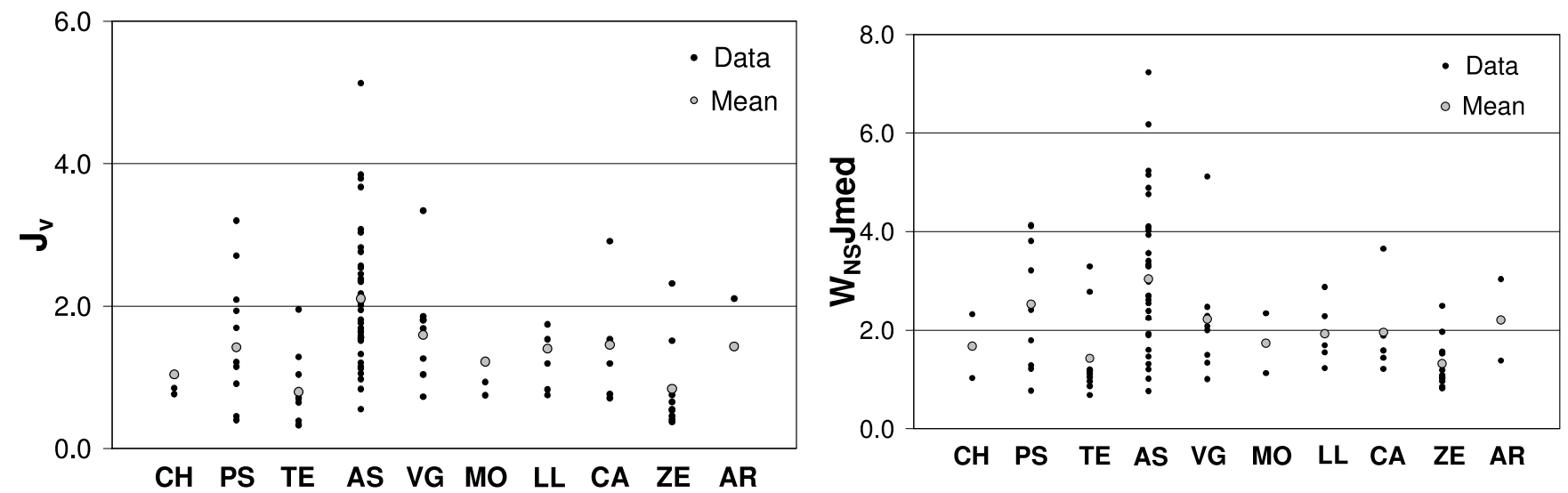

Fig. 8. Distributions of $J_{v}$ and $W_{N S} J m e d$ in the studied granites (granite abbreviations are as in Fig. 1).

of joints, and influences the identification of joint sets as shown by Sonmez et al. (2004), and a higher percentage of joints will be classified as random.

Despite these considerations, which are always present in such an assessment, the values obtained express the importance of using a block size index considered as an image of the degree of jointing. The block size evaluation without the factors referred to above will not give a clear image of the degree of jointing, and consequently leads to poor quarry management. The proposed factors introduce small variations in the $W J$ indices; however, these differences are important in quarry management to define the places where exploration is profitable. According to the method employed in this study, the relationships encountered are valid for these granites, and caution must be used in their extrapolation to other rocks or tectonic settings. The implementation of Weighted Jointing must be tested in other places or rocks for confirmation and improvement.

\section{Conclusions}

Quarry management is extremely dependent on the joint pattern, and any inaccuracy in its identification and characterization will have consequences in the estimated deposit yield. For these reasons, it is important to 
analyse the factors that influence the computation of the block size and improve their estimation to avoid inaccuracies. Information about jointing such as joint orientation, number of joint sets and respective orientation, spacing of each joint set and spacing of random joints is acquired in the rock mass surface, and thus sampling orientation biases associated with linear surveys may be avoided. The median spacing is a better way to represent the central tendency of the spacing distribution, and therefore it should be used instead of the mean spacing. Consequently, the indices estimated with median spacing are higher than those using the mean. I propose the weighting of joint sets according to the number $\left(W_{N S}\right)$ or the sum $\left(W_{S S}\right)$ of spacing data, the weighting of the random joints according to the number $\left(R J_{N S}\right)$ or the sum $\left(R J_{S S}\right)$ of spacing data, and the weighting of the joint pattern geometry by using the geometric factor $(G f)$. Four types of jointing weighting were defined according to the number or sum of spacing data and the mean or median spacing $\left(W_{N S} J, W_{N S} J m e d, W_{S S} J\right.$, and $W_{S S} J$ med), always considering the random joints and geometric factor. The distribution of the proposed indices best fits a lognormal theoretical distribution. The indices $W_{N S}$ Jmed and $W_{S S}$ Jmed furnish similar values, but the first is slightly higher as a consequence of the lower median spacing of the joint sets with more data and therefore is the most appropriate. The mean $W_{N S} J m e d$ value obtained for the studied granites is 2.33, whereas the mean $J_{v}$ is 1.56 . Regression analysis indicates a strong relation between the studied indices, establishing 1.30 as the $J_{v}$ threshold for profitable quarrying. These results emphasize the importance of considering factors other than the number of joint sets and mean spacing in block size assessment. Despite the number of study sites and the data considered in this study, it is recommended that this method should be applied in other granites in different tectonic settings.

Acknowledgements. The author is grateful to the Centro de Geociências-Universidade de Coimbra for providing partial financial support for this study, and also to the anonymous reviewers for their constructive comments and suggestions.

\section{References}

Bickel, D. 2003. Robust and efficient estimation of the mode of continuous data: the mode as a viable measure of central tendency. Journal of Statistical Computation and Simulation, 73, 899-912.

BlÈs, J.-L. \& Feuga, B. 1981. La fracturation des roches. BRGM, Manuels et Méthodes, 1.

Carlsson, A. \& Olsson, T. 1978. Joint apertures in a preCambrian crystalline rock mass in Sweden. Bulletin of the International Association of Engineering Geology, 18, 127130.

Carvalho, J.F., Henriques, P., Falé, P. \& Luís, G. 2008. Decision criteria for the exploration of ornamental-stone deposits: Application to the marbles of the Portuguese Estremoz Anticline. International Journal of Rock Mechanics and Mining Sciences, 45, 1306-1319.
Castaing, C. \& Rabu, D. 1981. Apports de la géologie à la recherche et l'exploitation de pierres de taille (roches ornementales et de construction). Bulletin du BRGM (2), Section III, 11, 81-97.

Davis, J.C. 1986. Statistics and Data Analysis in Geology. Wiley, New York.

Dutartre, P. 1982. Étude de la fracturation du granite de la Margeride (région de Saint-Alban-sur-Limagnole-Lozère). Géometrie, cinématique, densité des fractures. Documents du BRGM, 41.

Escuder Viruete, J., Carbonell, R., Jurado, M.J., Martí, D. \& Pérez-Estaún, A. 2001. Two-dimensional geostatistical modeling and prediction of the fracture system in the Albala Granitic Pluton, SW Iberian Massif, Spain. Journal of Structural Geology, 23, 2011-2023.

García, E.O. 1996. Investigación de yacimientos. In: JiMENo, C.L. (ed.) Manual de rocas ornamentales. Entorno grafico, Madrid, 139-174.

Hisanaga, K., Kudo, Y., Sano, O. \& Nakagawa, K. 1993. Preferred orientation of granite joints in Oshima, Southwest Japan. In: Pasamehmetoglu, A.G., Kawamoto, T., Whittaer, B.N. \& Aydan, O. (eds) Assessment and Prevention of Rock Failure in Rock Engineering. Balkema, Rotterdam, 543-548.

Hudson, J.A. \& HARRison, J.P. 1997. Engineering Rock Mechanics: an Introduction to the Principles. Elsevier, Oxford.

Hudson, J.A. \& Priest, S.D. 1979. Discontinuities and rock mass geometry. International Journal of Rock Mechanics Sciences and Geomechanics Abstracts, 16, 339-362.

ISRM 1978. Suggested methods for the quantitative description in rock masses. International Journal of Rock Mechanics and Mining Sciences, 15, 319-368.

JimenEZ-RodRiguez, R. \& SitAR, N. 2006. A spectral method for clustering of rock discontinuity sets. International Journal of Rock Mechanics Sciences and Geomechanics Abstracts, 43, 1052-1061.

KalenchuK, K.S., Diederichs, M.S. \& McKinnon, S. 2006. Characterizing block geometry in jointed rockmasses. International Journal of Rock Mechanics and Mining Sciences, 43, 1212-1225.

KalenchuK, K.S., McKinnon, S. \& Diederichs, M.S. 2008. Block geometry and rockmass characterization for prediction of dilution potential into sub-level cave mine voids. International Journal of Rock Mechanics and Mining Sciences, 45, 929-940.

Kulatilake, P.H.S., Wathugala, D.N. \& Stephansson, O. 1993. Joint network modeling with a validation exercise in Stripa mine. International Journal of Rock Mechanics Sciences and Geomechanics Abstracts, 30, 503-526.

Latham, J.-P., Meulen, J.V. \& Dupray, S. 2006. Prediction of in-situ block size distributions with reference to armourstone for breakwaters. Engineering Geology, 86, $18-36$.

Lu, P. \& Latham, J.-P. 1999. Developments in the assessment of in-situ block size distributions of rock masses. Rock Mechanics and Rock Engineering, 30, 29-49.

Marit, W., Meri-Lissa, A., Tuija, E., Matti, P. \& Juha, S. 2009. Structural evolution of the crust as a means of determining the technical properties of bedrock in the Helsinki capital region. In: Proceedings of the 10th IAEG International Congress. Geological Society, London, Engineering Geology Special Publications, 22, Paper 86.

Marre, J. 1986. The Structural Analysis of Granitic Rocks. North Oxford Academic Publishers, London.

Morais, A.I.F. 2003. Inventariação, Caracterização e Valorização das Pedreiras do Granito Amarelo Real. MS thesis, 
Universidade de Trás-os-Montes e Alto Douro, Vila Real, Portugal.

Munõz de la Nava, P., Escudero, J.A.R., Suarez, I.R., Romero, E.G., Rosa, A.C., Moles, F.C. \& Martinez, M.P.G. 1989. Metodología de investigación de rocas ornamentales: granitos. Boletín Geológico y Minero, 100, 433-453.

Nefeslioglu, H.A., Gokceoglu, C. \& Sonmez, H. 2006. Indirect determination of weighted joint density ( $w \mathrm{Jd}$ ) by empirical and fuzzy models: Supren (Eskisehir, Turkey) marbles. Engineering Geology, 85, 251-269.

Nikolayev, D., Siegesmund, S., Mosch, S. \& Hoffmann, A. 2007. Model-based prediction of unfractured rock masses. Zeitschrift der Deutschen Gesellschaft für Geowissenschaften, 158, 483-490.

PAlmströM, A. 1982. The volumetric joint count - a useful and simple measure of the degree of rock jointing. In: Proceedings of the 4th International Congress of the IEAG, Vol. 5. Balkema, Rotterdam, 221-228.

Palmström, A. 1996. The weighted joint density method leads to improved characterization of jointing. In: Proceedings of the Conference on Recent Advances in Tunnelling Technology, New Delhi.

PAlmström, A. 2000. Block size and block size distribution. In: Proceedings of the Workshop on Reliability of Classification Systems, GeoEng 2000 Conference, Melbourne [CD-ROM]

PAlmströM, A. 2001. Measurement and characterization of rock mass jointing. In: Sharma, V.M. \& Saxena, K.R. (eds) In-situ Characterization of Rocks. Balkema, Rotterdam, 49-97.

PAlmströM, A. 2005. Measurements of and correlations between block size and Rock Quality Designation (RQD). Tunneling and Underground Space Technology, 20, 362-377.

Pettifer, G.S. \& Fookes, P.G. 1994. A revision of the graphical method for assessing the excavatability of rock. Quarterly Journal of Engineering Geology, 27, 145-164.

Priest, S.D. 1993. Discontinuity Analysis for Rock Engineering. Chapman \& Hall, London.

Priest, S.D. \& Hudson, J.A. 1976. Discontinuity spacing in rock. International Journal of Rock Mechanics Sciences and Geomechanics Abstracts, 13, 135-148.

Priest, S.D. \& Hudson, J.A. 1981. Estimation of discontinuity spacing and trace length using scanline. International Journal of Rock Mechanics Sciences and Geomechanics Abstracts, 18, 183-197.

Prissang, R., Hellä, P., LehtimäKi, T., SAKsa, P., Nummela, J. \& VuENTO, A. 2007. Localisation of undisturbed blocks in larger dimension stone rock masses. Zeitschrift der Deutschen Gesellschaft für Geowissenschaften, 158, 471-482.
RAfieE, A. \& VINCHES, M. 2008. Application of geostatistical characteristics of rock mass fracture systems in 3D model generation. International Journal of Rock Mechanics and Mining Sciences, 45, 644-652.

REN, G. \& NIE, D. 2009. Quantitative evaluation of the classification of the unloading zone of a rock mass slope. In: Proceedings of the 10th IAEG International Congress. Geological Society, London, Engineering Special Publications, 22, Paper 546.

Selenon, O., Luodes, H. \& Ehlers, C. 2000. Exploration for dimensional stone-implications and examples from the Precambrian of southern Finland. Engineering Geology, 56, 275-291.

Sonmez, H. \& Ulusay, R. 2002. A discussion on the HoekBrown failure criterion and suggested modifications to the criterion verified by slope stability case studies. Yerbilimleri, 26, 77-99.

Sonmez, H., Nefeslioglu, H.A. \& Gokceglu, C. 2004. Determination of $\mathrm{wJd}$ on rock exposures including wide spaced joints. Rock Mechanics and Rock Engineering, 37, 403-413.

Sousa, L.M.O. 2000. Estudo da fracturação e das características físico-mecânicas de granitos da região de Trás-osMontes com vista à sua utilização como rocha ornamental. $\mathrm{PhD}$ thesis, Universidade de Trás-os-Montes e Alto Douro, Vila Real, Portugal.

SousA, L.M.O. 2007. Granite fracture index to check suitability of granite outcrops for quarrying. Enginnering Geology, 92, 146-159.

Sousa, L.M.O., SuÁrez del Río, L.M., Calleja, L., Ruiz de ArgandoñA, V. \& ReY, A.R. 2005. Influence of microfractures and porosity on the physico-mechanics properties and weathering of ornamental granites. Engineering Geology, 77, 153-168.

Taboada, J., Ordóñez, C., SaAvedra, A. \& Fiestras-Janeiro, G. 2006. Fuzzy expert systems for economical zonation of an ornamental slate deposit. Engineering Geology, 84, $220-228$.

Toyos, J.M., Taboada, J., Lombardero, M., Romero, J.A. \& Menendez, A. 1994. Estudio de las descontinuidades en yacimientos de roca ornamental. Boletín Geológico y Minero, 105, 110-118.

Wang, L.G., Yamashita, S., Sugimoto, F., Pan, C. \& Tan, G. 2003. A methodology for predicting the in situ size and shape distribution of rock blocks. Rock Mechanics and Rock Engineering, 36, 121-142.

Wines, D.R. \& LiLLY, P.A. 2002. Measurement and analysis of rock mass discontinuity spacing and frequency in part of the Fimiston Open Pit operation in Kalgoorlie, Western Australia: a case study. International Journal of Rock Mechanics and Mining Sciences, 39, 589-602. 